\title{
Saberes patrimoniais pesqueiros ${ }^{*}$
}

\section{Traditional fishermen`s knowledge*}

\author{
Lúcia Helena de Oliveira CUNHA**
}

\section{RESUMO}

Este artigo pretende configurar as distintas expressões de saber presentes na cultura dos pescadores tradicionais que propiciam a conservação da natureza e propõe uma reflexão sobre a possibilidade de diálogo entre saber patrimonial e saber científico.

Palavras-chave: pescador, saber, natureza.

\begin{abstract}
This work intends to configure the different expressions of knowledge presents in the culture of traditional fishermen that propitiate the conservation of the nature and it proposes a reflection on the possibilities of a dialogue among patrimonial knowledge and scientific formal knowledge in new historical arrangements.

Key-words: fisherman, knowledge, nature.
\end{abstract}

O modo como os chamados "povos da tradição" especificamente os pescadores artesanais ${ }^{1}$ - são simbolicamente representados reveste-se de significações próprias em conformidade com os distintos olhares do mundo urbano.

É corrente referir-se aos pescadores como povos atrasados, indolentes, preguiçosos, como se sua forma de or- ganização social fosse destituída de dinâmica e racionalidade.

Sob esse prisma, sua forma de trabalho - a pesca sequer é legitimada como tal, ignorando-se os múltiplos modos de produção ou de relacionamento do homem com a natureza - mediados pelo trabalho - que atravessam a história.

\footnotetext{
* Este artigo resulta de um conjunto de trabalhos realizados pela autora, em momentos distintos, como proposta de reflexão final centrada na questão do diálogos entre saberes ( em publicação/ NUPAUB-USP).

** Antropóloga, professora aposentada da Universidade Federal da Paraíba e consultora do NUPAUB/USP

1 Elaborando uma tipologia da produção pesqueira no litoral do Paraná, Andriguetto estabelece as práticas de pesca ali existentes. Para os interesses do presente estudo, depreende-se que a pesca artesanal subdivide-se na Pesca Rudimentar, que inclui as zonas com baixa intensidade tecnológica e baixa produção; e na Pesca Artesanal Diversificada de média tecnologia, que abrange as zonas de mais alta diversificação de práticas pesqueiras, mas de média intensidade tecnológica e baixa ou média produção. Essas últimas zonas correspondem às áreas estuarinas da APA de Guaraqueçaba, no litoral norte do Paraná, que, segundo o autor, "se apresentou assim como um espaço pesqueiro, com identidade própria" (ANDRIGUETTO FILHO, 1999).
} 
CUNHA, L. H. O. Saberes patrimoniais pesqueiros...

De outro lado, aludindo-se ao mito do paraíso perdido, os pescadores artesanais são vistos, muitas vezes, romanticamente vivendo no reino da natureza, quase como se com ele se confundissem, numa relação mimética. Essa visão idílica do pescador artesanal, centrada numa concepção fixa e exterior da natureza, tende a congelá-lo no tempo, como se fosse ausente de movimento, ausente de desordens.

Assim, por não se inscrever no ritmo veloz dos tempos modernos, que incessantemente parece anunciar a emergência de "novos tempos" (em termos reais e fantasmagóricos), o pescador artesanal ou os chamados caiçaras aparecem desprovidos de sentido de tempo - ou, mais especificamente, de tempo em movimento -, estando dessa maneira condenados a ser eternamente os mesmos, eternamente passado. Em tais termos é que a idéia de tradição é marcada pela idéia de repetição e estabilidade, não abrindo margem a variação enquanto a de modernidade é caracterizada pelo ritmo contínuo das mudanças, da novidade (CUNHA, 2002). ${ }^{2}$

De outro modo, entendendo tradição em movimento, Bornheim (1987) recorre ao sentido etimológico da palavra e assinala que "tradição vem do latim traditio e significa igualmente entregar, passar algo para outra pessoa, ou passar algo de uma geração a outra geração. Em segundo lugar, os dicionaristas referem a relação do verbo tradire com o conhecimento oral e escrito. Isso quer dizer que, através da tradição, algo é dito e o dito é entregue de geração a geração...".

Isso quer dizer que tradição é algo dinâmico, algo que transita, que se movimenta, contrariando assim o sentido convencional imputado à palavra (ou a processos histórico-sociais tradicionais). Sem desconhecer que há tradições e tradições, o que importa marcar aqui é "que algo é entregue" de geração a geração para reproduzir-se no tempo - ainda que ressignificado no fluxo da história.

Assim, olhar para o pescador artesanal (ou para o caiçara) como povo ausente de história, ultrapassado é ne- gar sua relação secular com o ambiente em que vive, negar todo conhecimento acumulado de sua reprodução social e dos ecossistemas em que vive.

Nesse sentido, além de destituírem o pescador artesanal de sua condição de humanidade, os olhares externos desconhecem que esse sujeito social tem uma forma de ordenação temporal e espacial dissonante daquela do contexto urbano-industrial e um conjunto de saberes patrimoniais decorrentes de sua interação secular com a natureza, dos quais a modernidade não pode prescindir para sua continuidade no tempo. Nisso, em que pesem as mudanças sociais que se vêm processando no interior das comunidades pesqueiras nas últimas décadas, descaracterizadas pela expansão da urbanização, do turismo e da especulação imobiliária em seus territórios (CuNHA, 1987-2000).

Embora a "produção artesanal pesqueira" esteja inscrita na chamada pequena produção mercantil simples portanto, subordinada desde sua gênese histórica ao "tempo do relógio"3 - é possível dizer que os pescadores artesanais ainda tecem seu próprio tempo num ritmo dissonante do ritmo urbano-industrial, pois suas vidas seguem os movimentos próprios da natureza - das marés, das espécies, dos astros e da atmosfera.

A rigor, é um ritmo que se funda, de um lado, na especificidade do ecossistema marinho, imprevisível, cíclico e móvel; e, de outro, na atividade produtiva - a pesca -, entrelaçada com a passagem das espécies nas águas (com seu ciclo biológico e movimento migratório), regulando o tempo de trabalho. Pode-se dizer, seguindo Thompson (1978), que há ainda um "tempo natural"4 no interior das comunidades pesqueiras regulando o seu tempo de trabalho, ainda que articulado a outras temporalidades. É a pesca que comanda os horários do dia-a-dia, a sucessão, o ordenamento das tarefas e seus intervalos, no entrelaçamento da atividade com a natureza (Cunha, 1987).

Não obstante já revele desarticulação de práticas e formas de saber vividas no passado, a pesca artesanal re-

2 Preocupado com os fenômenos que tendem a desarticular as formas tradicionais de organização social do pescador artesanal, assim coloca Vieira (1995, p. 306312): “... em termos mais concretos caberia empreender, num primeiro momento, a diversificação do potencial de recurso existente em cada microrregião litorânea, em sintonia com a valorização de formas tradicionais de conhecimento detidas pelos pescadores". A partir daí o autor propõe a Gestão Patrimonial de Ecossistemas Litorâneos.

3 Partindo do contraponto que Thompson estabelece entre o tempo do relógio e o tempo natural, entende-se por tempo do relógio toda produção e forma de ordenação social inscrita nos marcos do capitalismo, em que o relógio, como medida abstrata e externa de tempo, atua nos núcleos pesqueiros, em particular com a introdução de barcos motorizados, sofisticação dos apetrechos de pesca e intensificação da produção mercantil, com grau de dependência acentuado dos intermediários e presença intensa do turismo.

4 De acordo com Thompson (op. cit), utilizamos também a categoria tempo natural, que não deve ser confundida com tempo em si da natureza. Conforme observamos, o tempo natural se manifesta nos núcleos pesqueiros artesanais a partir da relação que os homens do mar têm com a atividade e seus ciclos naturais. 
quer todo um arsenal de conhecimento acumulado sobre o espaço marítimo, construído pela experiência, abstração e intuição. Nesse processo, é possível verificar na cultura tradicional dos pescadores artesanais uma noção tridimensional do espaço, que abrange seus distintos domínios de vida - mar, terra e céu - dotados de significado.

Ainda que de modo difuso e fragmentário em face das mudanças sociais que sofreram as comunidades pesqueiras nas últimas décadas - em especial os chamados caiçaras - a lua, de acordo com as representações sociais do pescador, é um dos astros que atua em seu universo eco-produtivo, favorecendo boas ou más pescarias. "A lua mexe com a pesca, a lua mexe com tudo." Tais expressões são muitas vezes evocadas pelos pescadores artesanais e integram particularmente o universo cósmico dos mais velhos. A lua é o principal componente que atua no ciclo da maré, condicionando a elevação do nível do mar, a força da corrente, influindo na presença do peixe no espaço aquático e na modalidade de captura (CUNHA; ROUGEULLE, 1989).

Os ventos também interferem na dinâmica pesqueira. Segundo moradores de Guaraqueçaba, o leste e nordeste seriam os melhores ventos para a pesca, particularmente para espécies como camarão, miraguaia, bagre e parati. Os ventos oeste e sudoeste, ao contrário, trazem dificuldades: "o oeste, o sudoeste são ruins para nós", diz um pescador da Ilha das Peças. No caso da pesca da tainha, existem características particulares: o vento sul, chamado "rebojo", faz baixar a temperatura ambiente, que "faz correr a tainha", e é esperado com impaciência na época da safra; ele condiciona a chegada dos cardumes pela costa, e as alterações que muitas vezes ocorrem fazem com que os cardumes tendam a se dividir.

A par dessa concepção tridimensional do espaço, há de se considerar o mar como locus privilegiado da reprodução social do pescador artesanal, onde a apropriação dos recursos pesqueiros se dá de forma indivisa. Embora essa apropriação não seja homogênea - realizando-se mediante o trabalho dos grupos pesqueiros - é possível configurar o mar como espaço de propriedade comum dos pescadores artesanais, do qual extraem sua sobrevivência, ainda que marcada por disputas, tensões e conflitos.

Aliás - convém salientar - esse espaço não configura apenas um espaço da sobrevivência material, mas um espaço de sociabilidades distintas, marcadas por arranjos próprios no desenvolvimento das diversas modalidades de pesca e por representações simbólicas, advindas da relação secular do pescador com o mar.

A rigor, entre uma profusão de imagens, plena de significações, "os pescadores articulam seu conhecimento acerca da natureza a partir de dois movimentos: o de estender a ela as suas próprias capacidades intelectiva e volitiva e de aceitar alguns de seus fenômenos como indecifráveis, constituindo os mistérios, que preferem admirar a desvendar" (SILVA, 2000, p. 92). ${ }^{5}$

Nesse contexto, é possível evidenciar que, apesar de toda sorte de estereótipos atribuídos ao pescador artesanal e das ameaças a seus territórios tradicionais, a apropriação do ecossistema marinho é mediada por um complexo sistema cultural marcado por um manejo sábio dos recursos pesqueiros que os homens do mar desenvolveram ao longo do tempo.

Em incursões realizadas anteriormente no litoral sul e nordeste do Brasil, pudemos observar, in loco, que há ainda nas comunidades pesqueiras pesquisadas um relativo estado de conservação - em particular no litoral norte do Paraná (Guaraqueçaba). ${ }^{6}$

Ressalte-se que esse estado de conservação é derivado da forma secular com que as populações tradicionais locais se apropriaram do espaço marítimo e de seus recursos, e de toda uma sabedoria oriunda de seu sistema de vida tradicional.

Assim, ao longo do tempo, tais populações pesqueiras desenvolveram - mediante a observação rigorosa da natureza e a experimentação - mecanismos de controle ecológico, como forma de adaptar-se ao seu espaço ecoprodutivo e, ao mesmo tempo, conservá-lo.

Tais formas conservacionistas envolvem desde a observação sistemática da natureza, de acordo com suas "leis"

5 Para Silva (2000,p.92) “as grandes diferenças que opõem a concepção 'científica' - intelectualista e voltada para a construção de um saber repousado sobre a 'objetividade', da nativa - holista e totêmica não ofuscam o que ambas podem manter de comum, visto que, voltando a Lévi-Strauss (1966), não só compartilham o critério exterior mas também respondem à "exigência de ordem que está na base (...) de qualquer pensamento humano".

6 Ver CUNHA; ROUGELLE. Comunidades litorâneas e unidades de proteção ambiental: convivência e conflitos; o caso de Guaraqueçaba (PR). São Paulo: NUPAUB - USP,1989. Esse estudo, além de levantamentos feitos em várias ilhas da região, em termos exploratórios, centrou-se em duas comunidades: Ilha das Peças e Tromomô - uma por desenvolver uma pesca típica de baía; caso de Tromomô - outra por incluir a pesca de interior de baía, a pesca de mar aberto; caso da Ilha das Peças. Esse estudo mostra que, embora sofrendo alterações, muitos dos processos ainda se mantém. 
e movimentos internos, até mitos, crenças, normas e tabus culturais, que concorrem para o equilíbrio e reprodução dos ecossistemas marinhos.

No contexto da relação sociedade-natureza, típica do universo dos caiçaras, é possível evidenciar tanto mecanismos de ordem natural quanto de ordem cultural regulando a vida social: entre os primeiros, citam-se, como exemplo, os chamados sistemas de alerta, que, por meio da combinação dos ventos, das condições da maré e da lua, indicam se as condições são favoráveis para as pescarias ou não. Na verdade, são mecanismos naturais que se interpõem no universo da pesca, porém elaborados ou apropriados socialmente a partir da observação, da experimentação e da cosmovisão. Esses "sistemas de alertas" são mecanismos que indicam as condições de perigo ou evitam o livre acesso de outros pescadores nos mesmos pontos - o que acabaria por levar ao esgotamento dos recursos.

Ademais, os pontos pesqueiros constituem mecanismos de controle ecológico, pois evitam que a apropriação dos recursos seja realizada de modo indiscriminado e generalizado, ocasionando seu esgotamento (MALDONADO, 1989). Em Guaraqueçaba, por exemplo, pudemos constatar que, no passado, os pescadores não capturavam os camarões no baixio, onde se encontravam os indivíduos jovens dessa espécie.

Recentemente, a bióloga Érika Fernandes Pinto (2002) desenvolveu um estudo nessa mesma região, especificamente em Barra do Superagüi, ${ }^{7}$ com a preocupação de configurar os modelos cognitivos presentes nos pescadores de pequena escala voltados para os aspectos etnotaxinômicos e etnoecológicos.

Para essa autora, os resultados do estudo revelam que os pescadores de Barra do Superagüi "possuem um conhecimento refinado e detalhado sobre os hábitos alimentares e das interações tróficas entre diferentes grupos de organismos, elaborando cadeias tróficas até seis níveis" (Fernandes Pinto, p. 2001). Isso revela um conhecimento extremamente detalhado dos peixes e de seu ambiente natural, assim como um refinado sistema classificatório, no qual a categoria peixe aparece numa extensa e hierárquica lista de 588 nomes distintos, que reflete riqueza e diversidade

Afora a identificação de tabus e restrições alimentares, numa incidência de 26 recursos pesqueiros relaciona- dos como tal, Fernandes Pinto (2002, p. 19) detectou 37 recursos marinho-estuarinos utilizados para a prevenção e tratamento de enfermidades, os quais podem ser classificados como elementos que integram a "medicina local", ainda que, como alerta a autora, em consequiência de processos sociais externos tenha ocorrido descaracterização e perda desse tipo de conhecimento, referido muitas vezes como "coisa dos antigos" ou "crendice" (FERNANDES PINTO, 2002, p. 20).

Em nosso estudo na Ilha das Peças, pudemos também constatar a existência de tabus alimentares que, direta ou indiretamente, concorriam como mecanismo conservacionista, tanto no universo da pesca quanto no da caça e da coleta. No período em que a mulher permanecia em "resguardo" após o parto, por exemplo, apenas algumas espécies eram comestíveis e outras sofriam proibição no interior do grupo doméstico e social.

Sobre o litoral paranaense é possível registrar, ainda, o estudo de Thomas (1997), que focaliza especificamente a Ilha do Mel, localizada na entrada da Baía de Paranaguá. Nesse estudo, a autora descreve as representações dos nativos acerca da vegetação da ilha, em parte de sua extensão.

Em suas origens, a população local - constituída de índios, brancos e negros - vivia da pesca artesanal e da agricultura. Segundo a autora, foi a partir das décadas de 70 e 80 que o turismo ali se intensificou, abalando sua dinâmica socioambiental.

Em face do turismo, do desmatamento e do superpovoamento, o Estado se viu compelido a criar medidas para controlar a ocupação desenfreada, ainda que as unidades de conservação ali instaladas não envolvam a população local nas formas de manejo socioambiental. É nesse contexto que se decreta a criação na ilha da Estação Ecológica, com 2 240,69 ha, e da Reserva Natural, com 345,79 ha - áreas que representam $93 \%$ do espaço total da Ilha.

Considerando a riqueza do universo socioambiental principalmente dos ilhéus mais velhos, cabe perguntar: Qual o espaço que restou para os nativos desenvolverem suas atividades tradicionais? Até que ponto essas unidades de conservação - que dicotomizam a relação sociedade-natureza - não acabaram por excluir o homem nativo de seu habitat natural e social?

Diante da importância do mato e dos manguezais da Ilha do Mel, Thomaz (1997) procurou captar "as represen- 
tações sociais que personificam elementos simbólicos constituídos num tempo longo, veiculados no imaginário social que geram significações e dão sentido à realidade".

Referindo-se aos vários ambientes que integram a Ilha do Mel, com foco no mato ou na floresta, os seguintes depoimentos sugerem uma percepção integrada do ecossistema da Ilha e das suas peculiaridade em vários momentos:

“...é do mato que a gente sobrevive, né, se só tivesse areia aqui não dava pra morar, o mato ajuda a segurar a terra..."

“... com árvore a Ilha fica mais segura, se tirar tudo, fica sem árvore (...) o que segura Ilha são as árvores.”

Outros estudos significativos sobre manejo sábio dos recursos naturais são os de Born ${ }^{8}$ e Rodrigues, ${ }^{9}$ nos quais as autoras focalizam a riqueza dessa mata, registrando a cultura do Vale do Ribeira e sua biodiversidade. Apesar da destruição que a Mata Atlântica vem sofrendo, principalmente a partir da década de 70 em consequiência da superexploração das espécies, em particular das brejaúvas para a produção de hashi em escala industrial, é possível ainda evidenciar a grande riqueza biológica, genética e cultural da região.

Embora tais riquezas sejam pouco conhecidas, "as comunidades locais e tradicionais e os grupos étnicos (índios e remanescentes de quilombos) que vivem nas áreas da mata atlântica, detêm grande conhecimento sobre a dinâmica e o uso de vários recursos naturais dessa mata..." (BORN e RODRIGUES, 1998)

Entre várias espécies (tucum, guamiova, cipós, taquara e bambu), esse estudo concentra suas observações na extração da brejaúva - uma palmeira robusta, com grande quantidade de espinhos negros. Os artesãos da região classificam dois tipos de brejaúva: a airi e airu, conhecidas também como preta e branca, respectivamente. Uma de suas características principais é de ser uma árvore fibrosa, popularmente chamada "marfim vegetal".

O florescimento da brejaúva ocorre na início do ano e sua frutificação em junho, atingindo sua maturação em janeiro, quando se dá a coleta dos frutos.
Baseadas em suas pesquisas, Born e Rodrigues salientam que há uma forma de manejo na extração das brejaúvas airí e airú, adquirida na longa vivência das populações tradicionais na região. Por exemplo, a extração do fruto da árvore comumente se realiza durante a lua minguante; caso contrário "sofre ataque de brocas". Ademais, segundo as autoras em questão, os artesãos diversificam as áreas visitadas para evitar o esgotamento dos frutos e "escolhem o indivíduo mais 'velho', pertencente a uma touceira, antes de cortálo próximo ao chão com uma machado ou serrote". Esse processo é seguido de um conjunto de critérios, desde a altura das árvores (deve ter cerca de $8 \mathrm{~cm}$ ), posição e densidade das folhas (quanto mais velha a brejaúva menor a densidade de suas folhas caídas no chão), até distribuição dos espinhos no caule (ao envelhecer, a brejaúva perde os espinhos da parte inferior do caule).

Cabe realçar que as populações tradicionais somente efetuam a extração de outras plantas da mesma touceira depois de 10 anos - tempo necessário para o nascimento e maturação de outros frutos. "A extração de uma palmeira muito jovem compromete o aproveitamento de seu marfim..." (BORN e RODRIGUES, 1998).

Após a extração é que as populações locais indicarão o tipo de artesanato mais adequado para cada material, observados os tamanhos dos gomos no caule. Da palmeira, os artesãos fazem colheres, botões, hashis, tomando vários cuidados antes de proceder ao corte, como, por exemplo, identificando as partes do marfim vegetal que poderão ser aproveitados como matéria-prima para as variedades de artesanato, incluídas as esculturas que, inspiradas na natureza da região, adquirem a forma de pássaros (garça, coruja, macuco) e outros animais da Mata Atlântica.

Em que pesem os fatores externos que ao longo do tempo ameaçam a reprodução da brejaúva, esse é outro exemplo significativo do manejo sábio desse marfim vegetal praticado pelas populações tradicionais.

Diegues $(1987,2001)$ tem também demonstrado exaustivamente em seus estudos a existência de várias técnicas de apropriação dos recursos pesqueiros com característica conservacionista, entre as quais cita mecanismos de controle ecológico fundados no conhecimento e no segredo dos pontos pesqueiros, nos quais os "mestres" da pesca

8 BORN, G. Plantas medicinais da Mata Atlântica (Vale do Ribeira-SP ): extrativismo e sustentabilidade. São Paulo, 2000. Tese (Doutorado em Saúde Pública Ambiental) - Departamento de Saúde Ambiental da Faculdade de Saúde Pública - Universidade de São Paulo.

9 RODRIGUES, E. Beleza da Mata Atlântica em Arte. São Paulo: Vitae Civilis, 1998 
CUNHA, L. H. O. Saberes patrimoniais pesqueiros...

evitam o livre acesso de outros pescadores, como já foi dito. Tais mecanismos são regulados por arranjos culturais próprios, pois a prioridade de acesso a esses pesqueiros é norteada por uma ética baseada no "respeito" e no compadrio. Cordell (1983) registra que o controle dos locais de pesca pelos mestres pode ocorrer também em função do ciclo lunar. Aliás, não podemos deixar de mencionar aqui a importância que a mestrança (MALDONADO, 1993) ou a atividade do "proeiro" adquire como bem patrimonial, expressando a sabedoria dos mais velhos, dos mais hábeis e experientes - daqueles que acumularam durante sua vida, de modo integrado, o saber-fazer.

Tais mecanismos, no conjunto, revelam a existência de um complexo sistema cultural engendrado com grande sabedoria das condições naturais da vida e integrada à natureza, a seus ciclos e movimentos. Resgatar esse sistema cultural dos povos do mar - ainda que ressignificado no contexto da modernidade - é um desafio que se coloca para a ciência e para a história. Uma nova relação sociedadenatureza implica, necessariamente, a valorização das formas tradicionais de produção.

Isso não significa elogio ao "primitivo", às formas tradicionais pesqueiras - sabe-se que, longe de um paraíso, tais formas sociais vivem entre ordens e desordens ordens e desordens são categorias reguladoras da vida humana, ainda que dotadas de historicidade. Trata-se apenas de "reengendrar" ou "reencarnar" essas formas sociais tradicionais, para que numa relação de troca possam transmitir seus saberes e fazeres, e desse modo a modernidade possa desenvolver um novo projeto civilizatório que contemple a tradição.

\section{O Sentido dos Saberes}

Não existe ninguém no mundo melhor que os selvagens, os camponeses e os provincianos para estudar profundamente e em todos os sentidos os seus próprios afazeres; assim, quando passam do Pensamento ao Fato, podeis encontrar as coisas mais completas. (BALZAC, apud LÉVI-STRAUSS)

O que se pretende realçar aqui é que, afora o valor em si dos saberes patrimoniais, eles não podem ser vistos como expressões congeladas - meras representações do passado. Tal maneira de pensar se insere na lógica ocidental, que elege a si própria, de modo absoluto, como a única expressão da razão - a medida de todas as coisas -, atribuindo às outras formas societárias um pensamento pré-lógico, inferior e irracional.

Quando as formas tradicionais do saber são reconhecidas, elas o são apenas como espelho de um tempo que já passou - um tempo fossilizado -, como se fossem racionalidades mortas. Ou, no máximo, quando se admite a legitimidade desse saber, é conferido a ele um status secundário - saber empírico que decorre meramente da experiência. Sabe-se que essas expressões do raciocínio integram o pensamento ocidental, fundado na lógica cartesiana que se configura polar, dicotômica e excludente.

Superar os limites dessa razão implica considerar que o pensamento do outro em sua originalidade seja portador do que Lévi-Strauss chama de "ciência do concreto", como expressão do "pensamento selvagem". Para ele,

...longe de serem, como muitas vezes se pretendeu, obra de uma "função fabuladora" que volta as costas à realidade, os mitos e os ritos oferecem como valor principal a ser preservado até hoje, de forma residual, modos de observação e de reflexão que foram (e sem dúvida permanecem) exatamente adaptados a descobertas de tipo determinado: as que a natureza autorizava, a partir da organização e da exploração especulativa do mundo sensível em termos de sensível. Essa ciência do concreto devia ser, por essência, limitada a outros resultados além dos prometidos às ciências exatas e naturais, mas ela não foi menos científica, e seus resultados não forma menos reais. Assegurados dez mil anos antes dos outros, são sempre o substrato de nossa civilização. (LÉVI-STRAUSS, 1989, p. 31)

Esse pensamento, que não se confunde necessariamente com o pensamento do selvagem, é provido de abstração e se apresenta como uma dimensão do pensamento universal. Tal como o pensamento científico, o pensamento mítico é analítico e sintético e, portanto, totaliza-dor (GODELIER, 1982).

Assim, nessa crise do pensamento contemporâneo, a construção de novos paradigmas requer o repensar tanto dos padrões dominantes que regem a relação homem-natureza na modernidade, quanto da cultura e da razão técnicocientífica em que se funda a lógica ocidental. Isso implica um novo projeto societário que venha a incorporar - num movimento contínuo de atualização e renovação - todo um saber secular ou milenar dotado de conteúdo cósmico e 
histórico, produzido numa relação íntima e direta com a natureza.

Está se referindo a todo um saber mítico, simbólico e cultural - patrimonial - que índios, seringueiros, pescadores, coletores - povos do mar, da terra e da floresta vêm produzindo em simbiose com os ciclos produtivos e naturais, em relação de profundo respeito ao meio em que se inserem. O conhecimento que possuem sobre os ecossistemas dos quais fazem parte e sobre a diversidade de espécies que ali habitam constitui um verdadeiro patrimônio de que a modernidade não pode prescindir para a continuidade da vida no planeta.

Segundo Carvalho (1992), "uma nova cientificidade implica uma ampla reflexão sobre a ciência tradicional". Para esse autor, o caráter dessa proposta, pensada já numa perspectiva "bioantropossocial" (uma vez que que dialoga com as ciências da vida e com as ciências do homem), não se ancora na justaposição de eficácias científicas, burocráticas e corporativas, mas no diálogo entre saberes de várias ordens, não apenas no âmbito disciplinar, mas com outras formas de conhecimento dotadas de lógicas culturais próprias.

Desse modo, trata-se não apenas de reconhecer outras formas de saber geradas pela humanidade, em seu caráter histórico e patrimonial, mas de buscar um intercruzamento ou complementaridade de perspectivas para a construção de novas configurações paradigmáticas. Conforme Edgard de Carvalho, "essas configurações paradigmáticas emergentes certamente conduzirão a um reencantamento da ciência que implicará uma redefinição dos laços sociais, no retorno do sujeito, na valorização da ética, no redimensionamento do imaginário e principalmente na abertura da razão" (CARVALHO, 1992).

Nesse sentido, tradição e modernidade, como termos que se combinam e se complementam em arranjos históricos distintos - e não como termos que se excluem - significam, como se viu, romper com a noção temporal dominante que se apresenta em sentido unidimensional.

Reconhecendo o estatuto e o valor de saberes milenares ou seculares, Enrique Leff propõe, em termos epistemológicos, um diálogo entre os saberes para a construção de um novo modelo de conhecimento centrado não apenas nos padrões da ciência formal. Assim, observa:

\begin{abstract}
...isso implica a necessidade de desconstruir a racionalidade que fundou e construiu o mundo, no limite da razão modernizadora que a conduziu a uma crise ambiental, para gerar um novo saber no qual se reinscreve o ser no pensar e se reconfiguram as identidades, mediante um diálogo de saberes (encontro, enfrentamento, entercruzamento, hibridação, complementação e antagonismo) na dimensão aberta pela complexidade ambiental para o reconhecimento e re-apropriação do mundo. (LEFF, 2001, p. 188-189)
\end{abstract}

$\mathrm{Na}$ mesma linha parece situar-se o pensamento de Antônio Carlos Diegues quando propõe o conceito de etnoconservação. Admitindo que a natureza faz parte da história e, portanto, reconhecendo a legitimidade das formas tradicionais de gestão dos recursos entre os caiçaras, assinala: “(...) a valorização do conhecimento e das práticas de manejos dessas populações deveria constituir uma das pilastras de um novo conservacionismo nos países do Sul. Para tanto deve ser criada uma nova aliança entre os cientistas e os construtores e portadores do conhecimento local, partindo de que os dois conhecimentos - o científico e o local - são igualmente importantes". (DIEGUES, 2000, p. 41-42)

Tais considerações exigem "soluções" criativas e originais que levem a uma recombinação dos termos, em que o novo e o velho possam se enlaçar de ricas e distintas maneiras, em novas sínteses. Em outros termos, o que se postula é a conjunção de "tradição" e "modernidade" (ou modernidade "com-tradição"10)

Pensar na possibilidade do intercruzamento de tradição e modernidade, eis o sentido dessa proposta; ou, como sugere Castoriadis,

...não haverá transformação radical, sociedade nova, sociedade autônoma a não ser pela nova consciência histórica, que implica ao mesmo tempo uma restauração do valor da tradição e uma outra atitude face a essa tradição, uma outra articulação entre essa e as tarefas do presente/futuro (CASTORIADIS, 1985, p. 305).

Isso requer pensar em novos paradigmas ou referenciais que permitam recolocar - ou reinventar - a tradi-

10 A expressão "modernidade e com-tradição" foi cunhada em reflexões conjuntas com o professor e geógrafo Carlos Walter Porto Gonçalves, da Universidade Federal Fluminense. Rio de Janeiro, 1996. 
ção (ou os saberes da tradição) em novos termos, como força viva e propulsora da história.

Ou seja, uma nova relação do homem com a natureza - fundada em nova ética - implica um olhar sábio para a frente e para trás. Isso requer não somente um esforço de ruptura com os abismos historicamente produzidos entre ciências do homem e ciências da vida, mas um diálogo fecundo com outras formas e expressões do saber e cosmovisões, tecidas ao longo do tempo, para a produção e recriação da biossociodiversidade.

\section{REFERÊNCIAS}

ANDRIGUETTO FILHO, J. M. Sistemas técnicos de pesca e suas dinâmicas de transformação no litoral do Paraná - Brasil. Curitiba, 1999. Tese (Doutorado em Meio Ambiente e Desenvolvimento) - Universidade Federal do Paraná Université Paris 7 - Université Bordeaux 2.

ALMEIDA, M.B. As colocações como forma social, sistema tecnológico e unidade de recursos naturais. São Paulo: [?], 1988.

BALANDIER, G. Le désordre: éloge du movement. Paris: Fayard, 1988.

BORHEIM, G. O conceito de tradição. In: Tradição/Contradição. Rio de Janeiro: Zahar, 1987.

BORN, G. C. C. Plantas medicinais da Mata Atlântica (Vale do Ribeira - SP ): extrativismo e sustentabilidade. [S.I.: s.n.], 2000.

CASTORIADIS, C. A experiência do movimento operário. São Paulo: Brasiliense, 1985. (A Invenção Democrática).

CUNHA, L.H.O. Entre o mar e a terra: tempo e espaço na Barra da Lagoa. São Paulo, 1987. Dissertação (Mestrado em Ciências Sociais) - Pontifícia Universidade de São Paulo.

. Tempo natural e tempo mercantil na pesca artesanal. São Paulo: Hucitec, 2001.

Tradição e modernidade: natureza, tempo e movimentos. São Paulo: PUC-SP, 1993-1998.

CUNHA, L. H.; ROUGELLE, M. D. Comunidades litorâneas e unidades de proteção ambiental: convivência e conflitos; o caso de Guaraqueçaba. São Paulo: NUPAUB-USP, 1989.

DIEGUES, A.C. Pescadores, camponeses e trabalhadores do mar. São Paulo: Ática, 1983.

. Diversidade ecológica e culturas tradicionais : o caso das comunidades caiçaras. São Paulo: NUPAUB-USP, 1988.
DIEGUES, A.C. Repensando e recriando as formas de apropriação comum dos espaços e recursos naturais. In: Espaços e recursos naturais de uso comum. São Paulo: NUPAUB/USP, 2001.

DIEGUES, A.C. Etnoconservação (Org.). São Paulo: Hucitec, 2000.

GODELIER, M. Pensamento Primitivo e Historicidade In: CARVALHO, E. (Org.). Godelier. São Paulo: Ática, 1981.

LÉVI-STRAUSS, C. A ciência do concreto. In: O Pensamento selvagem. Campinas: Papirus, 1989.

LEFF, E. Epistemologia ambiental. São Paulo: Cortez, 2001.

MALDONADO, S. Mestres e Mares. São Paulo: Annalume, 1993.

. A caminho das pedras: percepção e utilização da pesca simples. São Paulo: Hucitec, 2002.

MALDONADO, S. No mar: conhecimento e produção. In: DIEGUES, A. C. (Org.) A Imagem das Águas. São Paulo: Hucitec, 2002.

PINTO, É.F.; MARQUEZ, J.G. Etnoictiologia dos pescadores da Barra de Superagui, Guaraqueçaba/Pr: aspectos etnotaxonômicos, etnoecológicos e utilitários. São Paulo, 2002. Universidade Federal de São Carlos. Resumo.

SILVA, G. Tudo que tem na terra tem no mar: a classificação dos seres vivos entre os trabalhadores da pesca em Piratininga, RJ. São Paulo: Hucitec, 2000

THOMPSON, E.P. O tempo e a disciplina do trabalho e o capitalismo industrial. [S.I.: s.n.], [19-].

VIEIRA, P.V. Gestão patrimonial de recursos naturais: construindo o ecodesenvolvimento em regiões litorâneas. In: CAVALCANTI, C. (Org.). Desenvolvimento e natureza: estudos para uma sociedade sustentável. São Paulo: Cortez 